ISSN1027-5495. Functional Materials, 25, No.1 (2018), p. 138-143

\title{
Three-dimensional generalization and verification of structured bounding surface model for natural clay
}

\author{
Cui Yunliang, Wang xinquan, Zhou lianying \\ School of Engineering, Zhejiang University City College, Hangzhou, \\ Zhejiang, 310015, China
}

Received December 1, 2017

\begin{abstract}
As the proposed structured bounding surface model can only be used to solve planar strain problems of natural soft clay, a three-dimensional adaptive failure criterion is adopted to improve the model to capture the three-dimensional behaviors of natural soft clay. The threedimensional adaptive failure criterion incorporated in this model can cover the Lade-Duncan criterion and the Matsuoka-Nakai criterion as its special ones. The structured bounding surface model is generalized into three-dimensional stress space by using the three-dimensional adaptive failure criterion. After improved with the three-dimensional adaptive failure criterion, the model can be seen as a modified bounding surface model which considers the destructuration and three-dimensional behaviors and neglects the anisotropy of natural soft clay. The simulations of undrained compression and extension tests of K0 consolidation state Bothkennar clay shows the unimportance of neglecting anisotropy in this model. It was validated on Pisa clay that the improved model can simulate well the three dimensional behaviors of natural soft clay under true triaxial conditions.
\end{abstract}

Keywords: natural soft clay, bounding surface, three-dimensional behavior, adaptive failure criterion

Рассмотрен трехмерный адаптивный критерий отказа трехмерного поведения естественной мягкой глины, в котором использованы критерий Ладэ-Дункана и критерий Мацуока-Накаи. Структурная модель ограничивающей поверхности обобщается на трехмерное пространство напряжений с использованием трехмерного адаптивного критерия отказа. После его учета модель может рассматриваться как модифицированная модель ограниченной поверхности, которая учитывает разрушающее и трехмерное поведение и пренебрегает анизотропией естественной мягкой глины. Проведено моделирование недренированных грунтов на сжатие и растяжение, а также состояния консолидации. Подтверждено, что предложенная модель может хорошо имитировать трехмерное поведение естественной мягкой глины при истинных трехосных условиях воздействия нагрузок.

Тривимірне узагальнення та перевірка структурованої моделі граничної поверхні для природної глини. Cui Yunliang, Wang xinquan, Zhou lianying.

Розглянуто тривимірний адаптивний критерій відмови тривимірної поведінки природної м'якої глини, в якому використано критерій ладе-дункана і критерій мацуока-накаї. Структурна модель обмеженої поверхні узагальнюеться на тривимірний простір напружень з використанням тривимірного адаптивного критерію відмови. Після його обліку модель може розглядатися як модифікована модель обмеженої поверхні, яка враховує руйнівну i тривимірну поведінку і нехтує анізотропією природної м'якої глини. Проведено моделювання недренованих грунтів на стиск і розтяг, а також стану консолідації. Підтверджено, що запропонована модель може добре імітувати тривимірну поведінку природною м'якої глини при істинних тривісних умовах впливу навантажень. 


\section{Introduction}

Experimental results [1, 2] indicate that the stress-strain relationship curve of natural clay has a softening after peak stress in triaxial compression with low confining pressure, and the compression rate of one-dimensional compression becomes faster when the compression pressure exceeds the structure yielding stress. To capture the structured behaviors of natural soft clay, many advanced constitutive models [3, 4] had been proposed. Based on the bounding surface concept initiated by Dafalias [5], AI-tabbaa and Wood [6] set a kinematic hardening yield surface, called 'bubble surface', inside the bounding surface to formulate a bubble model for soil. Rouainia and Wood [7] presented a structured bounding surface model, using the structure surface as the bounding surface and incorporating a structure measure of the bounding surface. The structure measure allows the size of the bounding surface to decay with plastic straining, so that the proposed model can describe the loss of structure. Taiebat et al. [8] suggested a destructuration law to address both isotropic and frictional destructuration and applied it on SANICLAY model. The frictional destructuration is proved to have significant effect on the loss of structure [8]. Literature [9] proposed a simple bounding surface model incorporating the destructuration law with some modifications. The proposed model can be seen as a simplified model of the existing structured bounding surface models [6-7], because it neglected some complex properties of soil, such as the kinematic hardening and anisotropy but considered the frictional destructuration. However, the model proposed by work [9] is two-dimensional constitutive model. it can only be used to solve planar strain problems of natural soft clay. It should be extended to be three-dimensional to capture the threedimensional problems of natural soft clay. In order to describe the three-dimensional deformation of natural soft clay more precisely, the proposed model is generalized in three-dimensional principal stress space with a three-dimensional adaptive failure criterion [10, 11]. The adopted criterion can cover the Lade criterion as well as the Matsuoka-Nakai criterion. The performance of the proposed model is verified by typical experimental results on intact samples of natural soft clay.

\section{Generalization of bounding surface model}

The yielding surface of bounding surface has the same elliptical shape with the Modified Cam-Clay model [7, 8]:

$$
F=\bar{p}^{2}-p_{c}{ }^{*} \bar{p}+\bar{q}^{2} / M^{* 2}
$$

where, $\bar{p}$ and $\bar{q}$ are the mean effective stress and the generalized shear effective stress of the mapping point on the bounding surface of the current stress point, respectively; $p_{c}{ }^{*}$ is the intersection point of the bounding surface and the axial of $p$, which denotes the size of the bounding surface; $M^{*}$ is the critical state stress ratio that is the slope of the critical state line. By definition:

$$
\bar{p}=\frac{\sigma_{1}+\sigma_{2}+\sigma_{3}}{3}
$$

$$
\bar{q}=\frac{1}{\sqrt{2}} \sqrt{\left(\sigma_{1}-\sigma_{2}\right)^{2}+\left(\sigma_{2}-\sigma_{3}\right)^{2}+\left(\sigma_{3}-\sigma_{1}\right)^{2}}
$$

where $\sigma_{1}, \sigma_{2}, \sigma_{3}$ are principal stresses in threedimensional stress.

In the classical plastic theory, the basic constitutive equation can be expressed as follows:

$$
d \varepsilon^{p}=C_{p} \cdot d \sigma
$$

wherein $d \varepsilon^{p}$ is incremental plastic strain, $d \sigma$ is incremental stress, and $C_{p}$ is the plastic flexibility matrix.

According to the associated flow rule, the plastic flexibility matrix can be presented as [10]

$$
C_{p}=\frac{\frac{\partial F}{\partial \sigma}\left(\frac{\partial F}{\partial \sigma}\right)^{T}}{K_{p}}
$$

wherein $K_{p}$ is the plastic hardening modulus. It is necessary to define the plastic hardening modulus in constitutive model. Work [9] proposed a structured bounding surface model. As presented in [9],

$$
K_{p}=\bar{K}_{p}+\zeta P_{a}\left(\left(\frac{\partial F}{\partial \bar{p}}\right)^{2}+\left(\frac{\partial F}{\partial \bar{q}}\right)^{2}\right)\left(b^{\psi}-1\right)
$$

The expression of $\bar{K}_{p}$ in eq. (6) can be seen in Ref. [9]. $b$ is the measure of the distance between the loading surface which has been defined in work [9]. $\zeta$ and $\psi$ are interpolation parameters, reflecting the affect of the stress level on the modulus. Their values can be determined based on experimental curve fitting. $P_{a}$ denotes the initial size of the bounding surface on axial of $p$ in $p$ - $q$ stress space.

The model proposed by work [9] is proved to be efficient and accurate for simulating the degradation of structure of natural clay. However, this model can only predict the two-dimensional stress-strain relationship of natural for it is only a two-dimensional constitutive model. It can only be used to solve planar strain problems. As we know, engineering problems are of- 

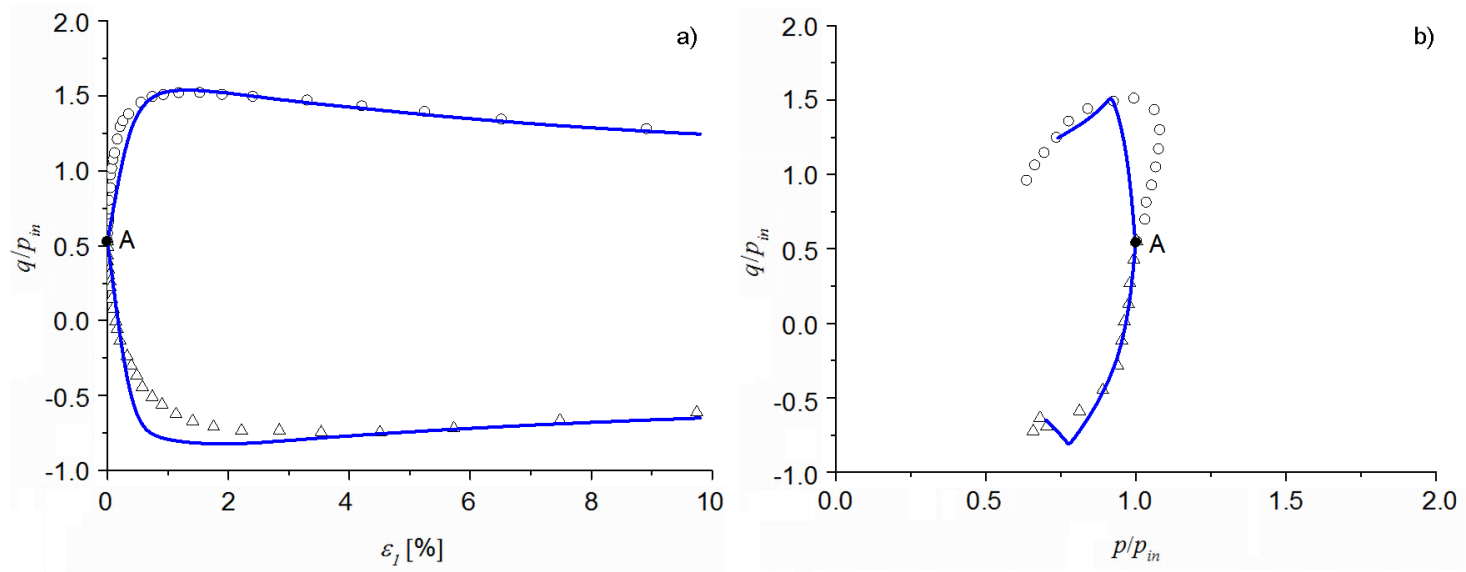

Fig. 1. Comparison of prediction (solid lines) and experimental data (symbols) for undrained stress paths and stress-strain curves of triaxial compression and extension tests on Bothkennar clay following the K0 state at point A. (a) Comparison of stress-strain curves;(b) Comparison of stress paths.

ten three-dimensional problems, which should be solved with three-dimensional constitutive models. Thus, in order to simulate the threedimensional behaviors of natural soft clay, a reasonable three dimensional adaptive failure criterion [10,11] will be introduced to revise the proposed model in [9]. An adaptive criterion adopted here almost covers all the criteria between the Lade-Duncan criterion and the Matsuoka-Nakai criterion in principal stress space by adjusting the adaptive parameter $\mu$ , including the Lade-Duncan criterion and the Matsuoka-Nakai criterion as its special cases. So, it is more adaptive compared with conventional criteria. The function of the three-dimensional adaptive failure criterion $[10,11]$ can be expressed as

$$
\begin{aligned}
& \frac{I_{1}^{3}+\mu I_{1} I_{2}}{I_{3}}= \\
& =\frac{\left(3-\sin \phi_{c}\right)^{3}+\mu\left(9-\sin ^{2} \phi_{c}\right)\left(1-\sin \phi_{c}\right)}{1-\sin \phi_{c}-\sin ^{2} \phi_{c}+\sin ^{3} \phi_{c}}
\end{aligned}
$$

where $\mu$ is a material constant which is determined by true triaxial test; $\phi_{c}$ is the critical state internal friction angle for triaxial compression; $I_{1}, I_{2}$ and $I_{3}$ are the first, second and third effective stress invariants, respectively.

$$
\left.\begin{array}{l}
I_{1}=\sigma_{1}+\sigma_{2}+\sigma_{3} \\
I_{2}=\sigma_{1} \sigma_{2}+\sigma_{2} \sigma_{3}+\sigma_{3} \sigma_{1} \\
I_{3}=\sigma_{1} \sigma_{2} \sigma_{3}
\end{array}\right\}
$$

$I_{1}, I_{2}$ and $I_{3}$ can be expressed as:

$$
\left.\begin{array}{l}
I_{1}=3 \bar{p} \\
I_{2}=3 \bar{p}^{2}-\frac{\bar{q}^{2}}{3} \\
I_{3}=\frac{1}{27}\left(27 \bar{p}^{3}-9 \bar{p} \bar{q}^{2}+2 \bar{q}^{3} \cos 3 \theta\right)
\end{array}\right\}
$$

wherein

$$
\theta=\arctan \frac{\sqrt{3}\left(\sigma_{2}-\sigma_{3}\right)}{2 \sigma_{1}-\sigma_{2}-\sigma_{3}}
$$

Substituting (10) into (8), equation (8) can be written as

$$
p^{3}-L_{2} q^{2} p+L_{3} q^{3}=0
$$

wherein $L_{2}$ and $L_{3}$ and $L_{2}$ are as follows:

$$
\begin{aligned}
& L_{2}=\left\{\begin{array}{l}
{\left[\left(3-\sin \varphi_{c}\right)^{3}+\mu\left(1-\sin \varphi_{c}\right)\left(9-\sin ^{2} \varphi_{c}\right)\right]-} \\
3 \mu\left(1-\sin \varphi_{c}-\sin ^{2} \varphi_{c}+\sin ^{3} \varphi_{c}\right)
\end{array}\right\} \\
&\left\{\begin{array}{l}
3\left[\left(3-\sin \varphi_{c}\right)^{3}+\mu\left(1-\sin \varphi_{c}\right)\left(9-\sin ^{2} \varphi_{c}\right)\right]- \\
27\left[(3+\mu)\left(1-\sin \varphi_{c}-\sin ^{2} \varphi_{c}+\sin ^{3} \varphi_{c}\right)\right]
\end{array}\right\} \\
&\left.L_{3}=\frac{2\left[\left(3-\sin \varphi_{c}\right)^{3}+\mu\left(1-\sin \varphi_{c}\right)\left(9-\sin ^{2} \varphi_{c}\right)\right] \cos (3 \theta)}{\left\{\begin{array}{l}
27\left[\left(3-\sin \varphi_{c}\right)^{3}+\mu\left(1-\sin \varphi_{c}\right)\left(9-\sin ^{2} \varphi_{c}\right)\right]- \\
(729+243 \mu)\left(1-\sin \varphi_{c}-\sin ^{2} \varphi_{c}+\sin ^{3} \varphi_{c}\right)
\end{array}\right\}}\right\}
\end{aligned}
$$

It should be noted that $L_{2}$ and $L_{3}$ are only used to denote complex expressions, and they have no physical meanings.

Derived from mathematical calibration, the shaping function of the criterion can be defined as $[10,11]$

$$
g(\theta)=\frac{\cos \left\{\frac{1}{3} \arccos \left[-\frac{3 \sqrt{3} L_{3}}{2 L_{2}^{3 / 2}}\right]\right\}}{\cos \left\{\frac{1}{3} \arccos \left[-\frac{3 \sqrt{3} L_{3} \cos 3 \theta}{2 L_{2}^{3 / 2}}\right]\right\}}
$$

Bounding surface revised by the three-dimensional adaptive failure criterion can be expressed as 


$$
F=\bar{p}^{2}-p_{c}^{*} \bar{p}+\frac{\bar{q}^{2}}{M^{* 2} g^{2}(\theta)}
$$

where $p_{c}^{*}=S_{i} p_{c}$ and $M^{*}=S_{f} M . S_{i}$ is an isotropic destructuraion factor and $S_{f}$ is a frictional destructuraion factor.

Solving the partial derivatives of Eq. (15) with respect to $\bar{p}, \bar{q}$ and $\theta$, respectively, it comes that

$$
\begin{gathered}
\frac{\partial F}{\partial \bar{p}}=2 \bar{p}-S_{i} p_{c} \\
\frac{\partial F}{\partial \bar{q}}=\frac{2 \bar{q}}{S_{f}^{2} g^{2}(\theta) M^{2}} \\
\frac{\partial F}{\partial \theta}=\frac{-2 \bar{q}^{2} g^{\prime}(\theta)}{S_{f}^{2} M^{2} g^{3}(\theta)}
\end{gathered}
$$

In Eq. (17), $g^{\prime}(\theta)$ is the derivative of $g(\theta)$ with respect to $\theta$.

Work [9] has already presented the expression of plastic modulus at the bounding surface $\bar{K}_{p}$. To generalize the expression of $\bar{K}_{p}$ into three-dimensional stress space, it can be revised by multiplying $M$ by $g(\theta)$ in the expression of $\bar{K}_{p}$ in work [9]. $M$ is the critical state stress ratio which is determined by the slope of the critical state line. Thus $\bar{K}_{p}$ can be written as,

$$
\begin{aligned}
& \bar{K}_{p}=S_{i} \bar{p} \frac{\left(1+e_{0}\right) p_{c}}{\lambda-\kappa} \frac{\partial F}{\partial \bar{p}}- \\
& -p_{c} \bar{p} \frac{\left(S_{i}-1\right)^{m_{i}}}{\lambda-\kappa} \sqrt{(1-\beta)\left(\frac{\partial F}{\partial \bar{p}}\right)^{2}+\beta\left(\frac{\partial F}{\partial \bar{q}}\right)^{2}}- \\
& -\frac{2 \bar{q}^{2}}{g^{2}(\theta) M^{2} S_{f}^{3}} \frac{\left(S_{f}-1\right)^{m_{f}}}{\lambda-\kappa} \sqrt{(1-\beta)\left(\frac{\partial F}{\partial \bar{p}}\right)^{2}+\beta\left(\frac{\partial F}{\partial \bar{q}}\right)^{2}}
\end{aligned}
$$

where [9]

$$
\begin{gathered}
\bar{S}_{i}=-\frac{\left(S_{i}-1\right)^{m_{i}}}{\lambda-\kappa} \bar{\varepsilon}_{d}^{p} \\
\bar{S}_{f}=-\frac{\left(S_{i}-1\right)^{m_{f}}}{\lambda-\kappa} \bar{\varepsilon}_{d}^{p} \\
\dot{\varepsilon}_{d}^{p}=\sqrt{(1-\beta) \dot{\varepsilon}_{v}^{p 2}+\beta \dot{\varepsilon}_{q}^{p 2}}
\end{gathered}
$$

In eq. (18)-(21), $\lambda$ and $\kappa$ are the slopes of the compression line and the swelling line in a volumetric strain-logarithmic mean stress plane, respectively. $m_{i}$ and $m_{f}$ are material constants which are determined by fitting the stress-strain curve of triaxial compression. $\dot{\varepsilon}_{v}^{p}$ is volumetric plastic strain rate and $\dot{\varepsilon}_{q}^{p}$ is deviatoric plastic strain rate. $\beta$ is a material con-

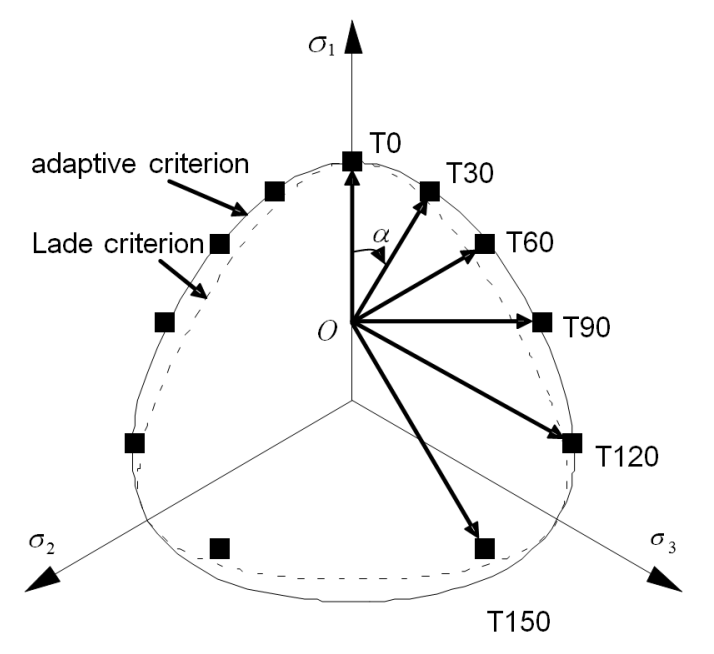

Fig. 2. Stress paths and failure points of true axial tests of Pisa soft clay

stant distributing the effect of volumetric and deviatoric plastic strain rates to the value of $\dot{\varepsilon}_{d}^{p}$ . $\beta$ could be set to 0.5 as a default value. $S_{i} S_{f}$ The initial values of $S_{i}$ and $S_{f}$ are needed in calculating with the proposed model. The initial isotropic destructuraion parameter $S_{i 0}$ is determined by one-dimensional compression test and initial frictional destructuraion parameter $S_{f 0}$ is determined by triaxial compression test. $e_{0}$ is the initial void ratio.

The plastic modulus at the current stress point, that is $K_{p}$, can be derived by substituting Eq. (18) into Eq. (6).

\section{Model verification}

Natural soft clays are mainly in the state of $\mathrm{K}_{0}$ state which is an anisotropic state. To keep the proposed model simple, the anisotropy feature of natural soft clay is neglected. However, this model is believed to be able to well capture the behaviors of natural anisotropic clay when structure is the main feature of the clay. In order to prove this statement and show the unimportance of neglecting anisotropy, the proposed model is used to simulate the undrained triaxial compression and extension tests on intact samples of Bothnennar clay following the in-situ $\mathrm{K}_{0}$ state. The mechanical response and stressstrain relationship of Bothkennar clay have been studied by Smith et al. [12] and Taiebat et al. [8], respectively. The samples were taken with Laval and Sherbrooke samplers from depths of 5.3-6.2 $\mathrm{m}$ and only the experimental data of Laval samples is used in this work. The samples were reconsolidated to in-situ $\mathrm{K}_{0}$ state before shear test. The $\mathrm{K}_{0}$ state stresses are $\sigma_{1}=46 k P a, \sigma_{2}=\sigma_{3}=28 k P a$. Then, the initial mean effective stress $p_{\text {in }}=34 k P a$. 

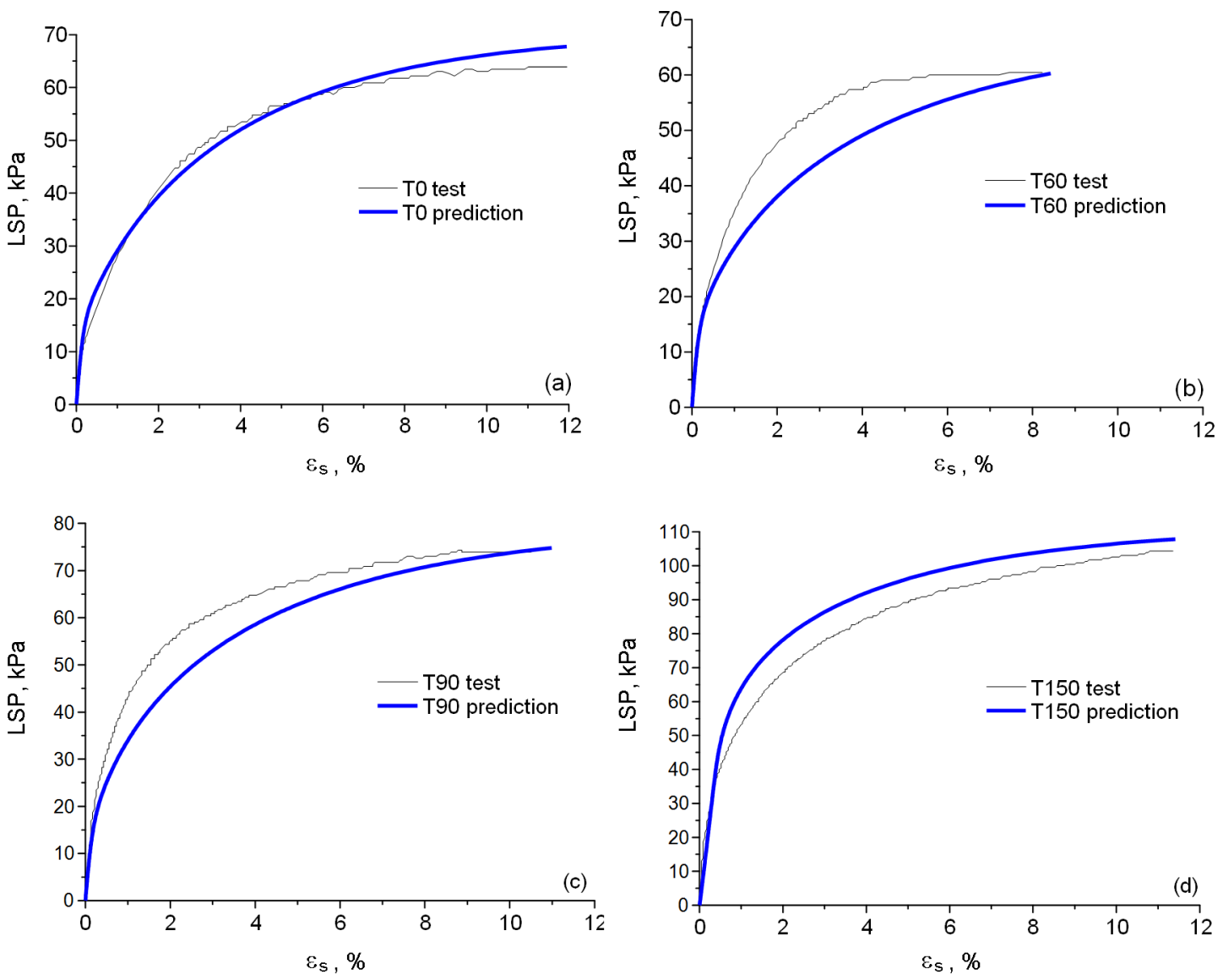

Fig. 3. Comparisons of experimental and simulation curves of the relationships of LSP versus following the T0, T60, T90 and T150 stress paths for Pisa clay.

The stress-strain data of the undrained triaxial compression and extension tests on intact samples of Bothnennar clay following the insitu $\mathrm{K}_{0}$ state is shown in Figure 1 by discrete points. To simulate the experiments, the proposed constitutive model proposed in this work is coded in FORTRAN. The parameters for the proposed model are obtained according to the study of Smith et al. [12] and Taiebat et al. [8] and shown in Table 1. The lines in Figure 1 show the stress-strain curve obtained by the simulation.

In Figure $1, p_{i n}$ is the initial mean effective stress which equal to $34 k P a, \varepsilon_{1}$ is the axial strain in compression or extension test. It can be seen in Figure 1 that the simulation stressstrain curves of the triaxial compression and extension tests both show good match to the experimental data. Thus, The proposed model is accurate for simulating the destructuration of natural clay. From a practical point of view, it is acceptable to neglect the anisotropy feature in the proposed model for natural soft clay to keep the model simple.

The samples of the true triaxial compression tests performed by Callisto $[2,13]$ were sampled under the Pisa tower. All of them were reconsolidated to the in-situ stress state at point $O$ of Figure 2 $\left(\sigma_{1}=113.5 \mathrm{kPa}, \sigma_{2}=\sigma_{3}=75.5 \mathrm{kPa}\right)$. From point $O$, drained compression tests were performed along rectilinear stress paths with different orientations in the stress space. Tests are labeled with the prefix ' $\mathrm{T}$ ', followed by a relevant value of angle $\alpha$. In Figure 2, the rectangular points are failure stress point normalized in plane $\pi$. Choosing an appropriate value for the adaptive parameter $\mu$ and fitting the failure points with the three-dimensional adaptive failure criterion gives the optimized fitting curve in Figure 2 with $\mu=1.5$. Adaptive crite-

Table 1. Parameters of the model for Bothkennar clay

\begin{tabular}{|c|c|c|c|c|c|c|c|c|c|c|}
\hline$\lambda$ & $\kappa$ & $\nu$ & $\mathrm{M}$ & $S_{i 0}$ & $S_{f 0}$ & $m_{i}$ & $m_{f}$ & $\beta$ & $\varsigma$ & $\psi$ \\
\hline 0.255 & 0.03 & 0.2 & 1.4 & 6.0 & 1.3 & 1.0 & 1.0 & 0.5 & 15.0 & 0.8 \\
\hline
\end{tabular}


Table 2. Parameters of the model for Pisa clay

\begin{tabular}{|c|c|c|c|c|c|c|c|c|c|c|c|}
\hline$\lambda$ & $\kappa$ & $\nu$ & $\mathrm{M}$ & $S_{i 0}$ & $S_{f 0}$ & $m_{i}$ & $m_{f}$ & $\beta$ & $\varsigma$ & $\psi$ & $\mu$ \\
\hline 0.110 & 0.024 & 0.2 & 0.983 & 3.0 & 1.4 & 0.9 & 0.9 & 0.5 & 12.0 & 1.1 & 1.5 \\
\hline
\end{tabular}

rion in Figure 2 means the three-dimensional adaptive failure criterion expressed by eq.(7). It can be seen in Figure 2 that the adaptive criterion can fit the failure points better compared with the lade criterion, except of the failure point of test T150. The inaccuracy in fitting the failure point of test T150 is caused by the limit of the adopted three-dimensional adaptive failure criterion that this criterion is isotropic but natural soils are always anisotropic. It seems that the anisotropy of soil should be considered in later research.

To verify the proposed constitutive model generalized by the three-dimensinal failure criterion, the model is computed in FORTRAN and used to simulate the true triaxial compression tests on natural Pisa clay. The optimized values of the parameters $m_{i}, m_{f}, \varsigma$ and $\psi$ are obtained by adjusting the values to fit the experimental curve of test $\mathrm{T} 0$ with the proposed model. The simulation of other tests takes the same model parameters with test T0. The model parameters are listed in Table 2 . The comparisons of simulation (heavy line) and observation (thin line) of tests T0, T60, T90 and T150 are shown in Figure 3. $L S P$ and $\varepsilon_{s}$ denote the lengths of stress path and the deviatoric strain invariant, respectively. The expressions are

$$
L S P=\sqrt{\left(\sigma_{1}-\sigma_{2}\right)^{2}+\left(\sigma_{1}-\sigma_{3}\right)^{2}+\left(\sigma_{2}-\sigma_{3}\right)^{2}}
$$

and

$$
\varepsilon_{s}=\sqrt{2 / 3}\left[\left(\varepsilon_{1}-\varepsilon_{2}\right)^{2}+\left(\varepsilon_{1}-\varepsilon_{3}\right)^{2}+\left(\varepsilon_{2}-\varepsilon_{3}\right)^{2}\right]^{1 / 2}
$$

where $\varepsilon_{1,2,3}$ are axial strains in true triaxial compression respectively. It can be seen that the simulation curves can well fit the experimental curves. Therefore, the proposed model is demonstrated to be able to well capture the behaviors of natural soft clay under general stress conditions.

\section{Conclusions}

The three dimensional adaptive failure criterion incorporated in this model can cover the Lade-Duncan criterion and the MatsuokaNakai criterion as its special ones. It is a good choice to use this failure criterion to generalize the bounding surface model into three-dimensional space.

The proposed model improved with the three dimensional adaptive failure criterion can cap- ture the three-dimensional behaviors of natural clay, but neglect the anisotropy of natural soft clay. However, it can be proved by simulations of undrained compression and extension tests of $\mathrm{K} 0$ consolidation state Bothkennar clay, that it is not important to neglect anisotropy in this model.

It can be verified by simulating the true triaxial tests of Pisa clay, that improved model can simulate the three dimensional behaviors of natural soft clay under true triaxial conditions.

\section{Acknowledgements}

The support of National Natural Science Foundation of China(Grant no. 51508507), Zhejiang Provincial Natural Science Foundation of China (Grant no. LQ16E080007), and Zhejiang Provincial Transportation Bureau Scientific Research Plan (Grant no. 2017004) are gratefully acknowledged.

\section{References}

1. D. Wang and L. Korkiala-Tanttu, , Engin.Geol., 214, 20, 2016.

2. L. Callisto, G. Calabresi, Géotechn, 48, 495, 1998.

3. E. L. Liu, H. S. Yu, C. Zhou, et al, Intern. J.Geomech., 17, 1, 2017.

4. Amir Hamidi, Saeed Tourchi and Fatemeh Kardooni, J. Rock Mech. Geotechn.Eng., 9, 1094, 2017.

5. Y. F. Dafalias, L. R. Herrmann, J. Eng. Mech. ASCE, 112, 1263, 1986.

6. A. AI-Tabbaa, D. M. Wood, Proceeding of the 3rd International Conference on Numerical Models in Geomechanics, Niagara Falls, pp.91-99, 1989.

7. M. Rouainia, D. M. Wood, Géotechn., 50, 153, 2000.

8. M. Taiebat, Y. F. Dafalias, R. Peek, Intern. J. Num. Anal. Meth. Geomech., 34. 1009, 2010.

9. Y. L. Cui, X. Q. Wang, S. M. Zhang, Functional Materials, 24. 628, 2017.

10. Y. Xiao, H. L. Liu and R. Y. Liang, Scie. China Ser.E, 54, 805, 2011.

11. Y. Xiao, H. L. Liu, J. G. Zhu, et al., Scie. China Ser.E, 55, 2877, 2012.

12. P. R. Smith, R. J. Jardine, D. W. Hight, Géotechn.,42, 257, 1992.

13. L. Callisto L, A. Gajo, D. M. Wood, Géotechn., 52, 649, 2002. 